\title{
Ampliação da segurança alimentar através de material gastronômico com espécies nativas da região Sudeste do Brasil
}

\section{Increasing food security through gastronomic material with native species from \\ Southeastern Brazil}

\section{Andrea Carvalheiro Guerra Matias \\ Paola Biselli Ferreira Scheliga ${ }^{2}$}

O Brasil é o principal país dentre os considerados de megabiodiversidade. Esse patrimônio representa um dos principais ativos brasileiros com papel estratégico na solidificação do desenvolvimento nacional. O Bioversity International e o PNUMA, órgãos vinculados à Organização das Nações Unidas para a Agricultura e Alimentação (FAO), convidaram o Brasil, o Quênia, o Sri Lanka e a Turquia para o projeto Biodiversity for Food and Nutrition (Projeto BFN), que teve por objetivo a conservação e a promoção do uso sustentável da biodiversidade para melhorar a segurança alimentar e a nutrição humana. Historicamente, o Brasil possui notoriedade por sua variedade cultural também retratada no campo da alimentação. Todavia, alimentos nativos reconhecidamente nutritivos e saborosos foram gradativamente sendo esquecidos ou desvalorizados, até o ponto de serem desconhecidos por grande parte da população local. Dentre as iniciativas brasileiras do Projeto BFN surgiu a proposta de elaboração de um material técnico gastronômico (livro). O presente trabalho apresenta os dados de um recorte deste projeto. As espécies alimentícias nativas utilizadas foram propostas pela Iniciativa "Plantas para o futuro": Araçá, Cambuci, Crumixama, Jenipapo, Major Gomes, Mangaba, Mangarito, Pequi, Taioba. Para avaliação das características sensoriais e potenciais usos das espécies foram conduzidas oficinas de reconhecimento dos frutos, com posterior prospecção de receitas. As propostas foram testadas e validadas com posterior produção fotográfica. Como resultado, foram desenvolvidas 38 produções. A distribuição das preparações segundo contribuição ao cardápio foi de $37 \%$ pratos principais, $26 \%$ sobremesas, $17 \%$ entradas, 10 acompanhamentos, $6 \%$ quitandas e bolos e $4 \%$ pães. Estas produções foram reunidas a iniciativas de mesmo caráter da própria região Sudeste e demais regiões do Brasil no livro Biodiversidade Brasileira: Sabores e Aromas, publicado pelo Ministério do Meio Ambiente (2018). O desenvolvimento de ações desta natureza, voltadas para a disseminação do uso de espécies nativas do Brasil, contribui para a promoção de demanda ao estudo das características físicas, químicas e nutricionais, com potencial aplicação de técnicas de manejo e conservação que viabilizem a comercialização e o uso destas espécies pela população; promove a melhoria e o incentivo de uma alimentação rica e completa nutricionalmente; e não obstante valoriza a Castronomia Brasileira e seu patrimônio cultural esquecido e/ou desconhecido por grande parte da população devido ao processo de urbanização e industrialização do país.

Palavras-chave: sustentabilidade; biodiversidade; dietética; espécies nativas; segurança alimentar. Keywords: sustainability; biodiversity; dietetic; native species; food security.

\footnotetext{
1 Doutora em Saúde Pública pela Universidade de São Paulo.

2 Mestre em Educação, Arte e História da Cultura pela Universidade Presbiteriana Mackenzie, docente e pesquisadora no curso de Gastronomia na Universidade Presbiteriana Mackenzie.
} 